\title{
A fully automated effervescence assisted dispersive liquid-liquid microextraction based on a stepwise injection system. Determination of antipyrine in saliva samples ${ }^{\text {负 }}$
}

\author{
Kseniia Medinskaia a, Christina Vakh ${ }^{\mathrm{a}}$, Darina Aseeva ${ }^{\mathrm{a}}$, Vasil Andruch ${ }^{\mathrm{b}, *}$, Leonid Moskvin ${ }^{\mathrm{a}}$, \\ Andrey Bulatov ${ }^{\mathrm{a}, *}$
}

a Department of Analytical Chemistry, Institute of Chemistry, Saint Petersburg State University, RU-198504 Saint Petersburg, Russia

${ }^{\mathrm{b}}$ Department of Analytical Chemistry, University of P.J. Šafárik, SK-04154 Košice, Slovakia

\section{H I G H L I G H T S}

- First attempt to automate the effervescence assisted dispersive liquidliquid microextraction.

- Automation based on Stepwise injection analysis manifold in flow batch system.

- Counterflow injection of extraction solvent and the effervescence agent.

- Phase separation performed by gentle bubbling of nitrogen.

- Application for the determination of antipyrine in saliva samples.

\section{A R T I C L E I N F O}

\section{Article history:}

Received 26 August 2015

Received in revised form 4 November 2015

Accepted 8 November 2015

\section{Keywords:}

Effervescence dispersive liquid-liquid microextraction

Automation

Stepwise injection analysis

Antipyrine

Saliva

\section{G R A P H I C A L A B S T R A C T}

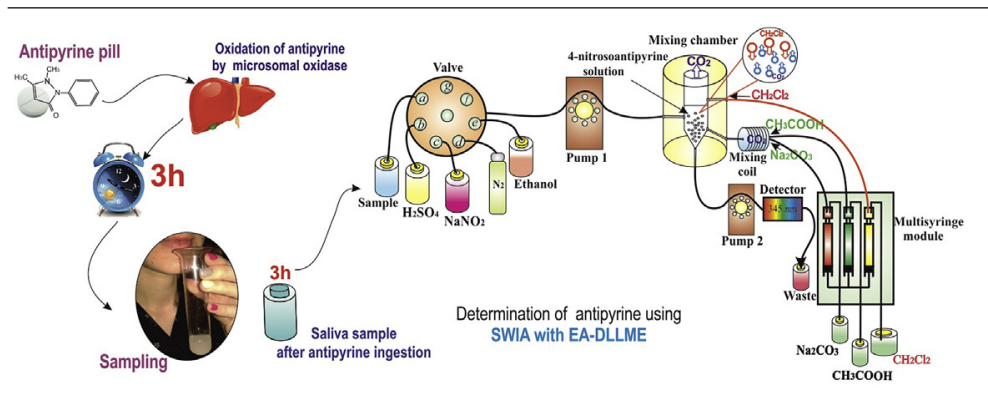

\begin{abstract}
A B S T R A C T
A first attempt to automate the effervescence assisted dispersive liquid-liquid microextraction (EADLLME) has been reported. The method is based on the aspiration of a sample and all required aqueous reagents into the stepwise injection analysis (SWIA) manifold, followed by simultaneous counterflow injection of the extraction solvent (dichloromethane), the mixture of the effervescence agent $\left(0.5 \mathrm{~mol} \mathrm{~L}^{-1}\right.$ $\mathrm{Na}_{2} \mathrm{CO}_{3}$ ) and the proton donor solution $\left(1 \mathrm{~mol} \mathrm{~L}^{-1} \mathrm{CH}_{3} \mathrm{COOH}\right)$. Formation of carbon dioxide microbubbles generated in situ leads to the dispersion of the extraction solvent in the whole aqueous sample and extraction of the analyte into organic phase. Unlike the conventional DLLME, in the case of EA-DLLME, the addition of dispersive solvent, as well as, time consuming centrifugation step for disruption of the cloudy state is avoided. The phase separation was achieved by gentle bubbling of nitrogen stream $\left(2 \mathrm{~mL} \mathrm{~min}{ }^{-1}\right.$ during $2 \mathrm{~min}$ ).

The performance of the suggested approach is demonstrated by determination of antipyrine in saliva samples. The procedure is based on the derivatization of antipyrine by nitrite-ion followed by EA-DLLME of 4-nitrosoantipyrine and subsequent UV-Vis detection using SWIA manifold. The absorbance of the yellow-colored extract at the wavelength of $345 \mathrm{~nm}$ obeys Beer's law in the range of $1.5-100 \mu \mathrm{mol} \mathrm{L}^{-1}$ of antipyrine in saliva. The LOD, calculated from a blank test based on $3 \sigma$, was $0.5 \mu \mathrm{mol} \mathrm{L}^{-1}$.
\end{abstract}

(c) 2015 Elsevier B.V. All rights reserved.

\footnotetext{
Selected paper from Flow Analysis XIII Conference, 5-10 July 2015 in Prague, Czech Republic.

* Corresponding authors.

E-mail addresses: vasil.andruch@upjs.sk (V. Andruch), bulatov_andrey@mail.ru (A. Bulatov).
}

\section{Introduction}

Sample preparation plays an important role in chemical analysis [1]. As usual, it includes the separation and/or pre-concentration 
of the analytes from the sample matrix with the improvements of selectivity and sensitivity. One of the most common separation and pre-concentration methods is the liquid-liquid extraction (LLE) characterized by simplicity and reliability. However, conventional LLE is time consuming and requires large amounts of organic solvents [2]. Currently, miniaturization; i.e., the significant reduction of the volume of hazardous solvents, which correspond to the concept of Green analytical chemistry (GAC), is of high demand [3]. Thus, aiming to improve the analytical performance of pre-treatment stage and satisfy the requirements of GAC, several liquid-liquid microextraction techniques have been developed [4,5]. One of them is dispersive liquid-liquid microextraction (DLLME), introduced by Rezaee et al., in 2006 [6].

Despite the obvious advantages, the DLLME has certain drawbacks which primarily result from requirements related to the extraction and dispersive solvents, since the addition of relatively high volume of dispersive solvent may increase the solubility of target analytes in aqueous phase. Various approaches such as, ultrasound-assisted emulsification microextraction [7], ultrasoundassisted surfactant-enhanced microextraction [8], vortex-assisted liquid-liquid microextraction [9] and vortex-assisted surfactantenhanced emulsification liquid-liquid microextraction [10,11], were reported to overcome this disadvantage.

Very recently, the effervescence assisted dispersive liquid-liquid microextraction (EA-DLLME) was reported by Valcárcel et al. [1214] and further developed by other researchers [15-17]. As usual, the EA-DLLME procedure involves adding $\mathrm{Na}_{2} \mathrm{CO}_{3}$ to an aqueous sample; after which an acid solution as proton donor, and an extraction solvent are added. As a result, $\mathrm{CO}_{2}$ microbubbles are generated. The extraction solvent is easily and homogeneously distributed into the sample, and target analytes are extracted into organic phase.

Another important and rapidly growing trend in modern analytical chemistry is the automation of analytical procedures. Flow based methods can be recognized as a universal tool for automation of a wide variety of analytical procedures, including DLLME $[18,19]$. Recently, there have been several approaches suggested for the implementation of various DLLME modes in flow systems, based on microcolumn phase separation [20], in-syringe approach [21], coupling with flow-batch sequential injection [22] and stepwise injection [23] systems, as well as, magnetic stirring [24]. However, to the best of our knowledge, the automation of EADLLME has not been reported yet.

Therefore, the aim of this work is to develop an approach for the automation of EA-DLLME. The stepwise injection analysis [2529] was chosen for this purpose. The extraction procedure has been optimized and applied for the determination of antipyrine in saliva samples. Antipyrine was selected as a model analyte due to the fact that antipyrine saliva half-life is widely used for the assessment of the activity of human hepatic mono-oxygenase system [30].

\section{Experimental}

\subsection{Chemicals and reagents}

All chemicals were of analytical reagent grade. Ultra-pure water was prepared by a Millipore Milli-Q purification system (Bedford, MA, USA). The $500 \mu \mathrm{mol} \mathrm{L}^{-1}$ stock solution of antipyrine was prepared by dissolving of the corresponding amount of the reagent (Aldrich, Germany) in water. The solution was stored in a dark place at $5{ }^{\circ} \mathrm{C}$ and used within 2 months. The working solutions were prepared daily by appropriate dilution of the stock solution with water. For antipyrine derivatization, the $6 \mathrm{mmol} \mathrm{L}^{-1}$ solution of sodium nitrite and $0.5 \mathrm{~mol} \mathrm{~L}^{-1}$ solution of sulfuric acid were used. The $0.5 \mathrm{~mol} \mathrm{~L}^{-1}$ solution of $\mathrm{Na}_{2} \mathrm{CO}_{3}$ and $1 \mathrm{~mol} \mathrm{~L}^{-1}$ solution of $\mathrm{CH}_{3} \mathrm{COOH}$ were used as effervescence agent and proton donor, respectively. Chloroform, tetrachloromethane, dichloromethane and tetrachloroethylene (Aldrich, Germany) were tested as extraction solvent. As a mobile phase, the methanol-phosphate buffer solution $(45: 55, \mathrm{v} / \mathrm{v})$ with $\mathrm{pH} 7$ was used. The phosphate buffer solution was prepared by mixing $60 \mathrm{mmol} \mathrm{L}^{-1}$ solution of $\mathrm{KH}_{2} \mathrm{PO}_{4}$ and $60 \mathrm{mmol} \mathrm{L}{ }^{-1}$ solution of $\mathrm{Na}_{2} \mathrm{HPO}_{4}(39: 61, \mathrm{v} / \mathrm{v})$. The $\mathrm{pH}$ was controlled with a $\mathrm{pH}$ meter.

\subsection{Sampling and sample preparation}

Human saliva samples were collected from volunteers after $3 \mathrm{~h}$ of antipyrine ingestion. Pills containing $0.6 \mathrm{~g}$ of antipyrine were ingested per os; after pre-rinsing the oral cavity with water. The samples were collected in previously-weighed polypropylene conical tubes, and re-weighed to calculate the amount of sample to be analyzed. Then, $2 \mathrm{~mL}$ of the sample was diluted with $3 \mathrm{~mL}$ of water, mixed and centrifuged at $5000 \mathrm{rpm}$ for $5 \mathrm{~min}$. The supernatant solution was collected and $1 \mathrm{~mL}$ of it was analyzed according to the developed SWIA procedure.

\subsection{SWIA manifold}

The SWIA manifold (Fig. 1) consists of a central eight-port selection valve (Cole-Parmer, USA); multisyringe module 4S (Crison, Spain) equipped with three $1 \mathrm{~mL}$ syringes and three 2-way solenoid valves; two peristaltic pumps (Cole-Parmer, USA) with modified PVC pumping tubes (Watson-Marlow, Russia) ensuring a reverse flow $\left(0.5-5 \mathrm{~mL} \mathrm{~min}^{-1}\right)$; PTFE mixing chamber $(10 \mathrm{~mm}$ in i.d., $5 \mathrm{~cm}$ at height) with channels from the side, top and bottom; PTFE mixing coil (1 mm i.d., $50 \mathrm{~cm}$ at length) and PTFE communication tubes $(0.5 \mathrm{~mm}$ i.d.). The manifold is equipped with a USB 4000 spectrophotometer (Ocean Optics Inc., USA), a $50 \mathrm{~mm}$ path length flow cell (FIAlab ${ }^{\circledR}$ Instruments Inc., Bellevue, USA) with the dead volume equal to $0.15 \mathrm{~mL}$, optical fibers QP400-2-UV-VIS (Ocean Optics Inc., USA) and a Model D 1000 CE UV light source (Analytical Instrument System Inc., USA). Data acquisition was performed using Sciware Systems ${ }^{\circledR}$ software.

\subsection{Procedure for the SWIA determination of antipyrine}

At the first stage (derivatization step), the solutions required for antipyrine derivatization were sequentially delivered into the mixing chamber (port 1) through the ports of the valve by the movement of the peristaltic pump (1) in the following order: $1 \mathrm{~mL}$ of the sample supernatant (or calibration standard solution) (port a), $1 \mathrm{~mL}$ of $0.5 \mathrm{~mol} \mathrm{~L}^{-1} \mathrm{H}_{2} \mathrm{SO}_{4}$ (port b) and $1 \mathrm{~mL}$ of $6 \mathrm{mmol} \mathrm{L}^{-1}$ $\mathrm{NaNO}_{3}$ (port c). To stir the solutions, a flow of nitrogen gas was passed through port $\mathbf{d}$ at a rate of $1 \mathrm{~mL} \mathrm{~min}^{-1}$ for $6 \mathrm{~min}$.

At the second stage (EA-DLLME step), the solenoid valves of the multisyringe module were switched to position ON (left) in order to fill syringe with $0.5 \mathrm{~mol} \mathrm{~L}^{-1} \mathrm{Na}_{2} \mathrm{CO}_{3}, 1 \mathrm{~mol} \mathrm{~L}^{-1} \mathrm{CH}_{3} \mathrm{COOH}$ and dichloromethane. The valves of the multisyringe module were switched to position OFF (right) in order to sequentially inject $300 \mu \mathrm{L}$ of $0.5 \mathrm{~mol} \mathrm{~L}^{-1} \mathrm{Na}_{2} \mathrm{CO}_{3}, 300 \mu \mathrm{L}$ of $1 \mathrm{~mol} \mathrm{~L}^{-1} \mathrm{CH}_{3} \mathrm{COOH}$ (port 3) and $300 \mu \mathrm{L}$ of dichloromethane (port 2) into the MC containing 4-nitrosoantipyrine solution (obtained in the derivatization step) in counterflow mode at a flow rate of $1.5 \mathrm{~mL} \mathrm{~min}^{-1}$. The solutions of $\mathrm{Na}_{2} \mathrm{CO}_{3}$ and $\mathrm{CH}_{3} \mathrm{COOH}$ were mixed in the mixing coil before that. After the extraction was finished (1 min), a flow of nitrogen gas was passed through port $\mathbf{d}$ at a rate of $2 \mathrm{~mL} \mathrm{~min}^{-1}$ for $2 \mathrm{~min}$; to remove the $\mathrm{CO}_{2}$ bubbles by movement of the peristaltic pump (1). Nitrogen was supplied from a portable tank (pressure less than $0.1 \mathrm{mPa}$ ).

At the final stage (detection), the extract was moved from the $\mathrm{MC}$ into the flow cell of the detector through the peristaltic pump 


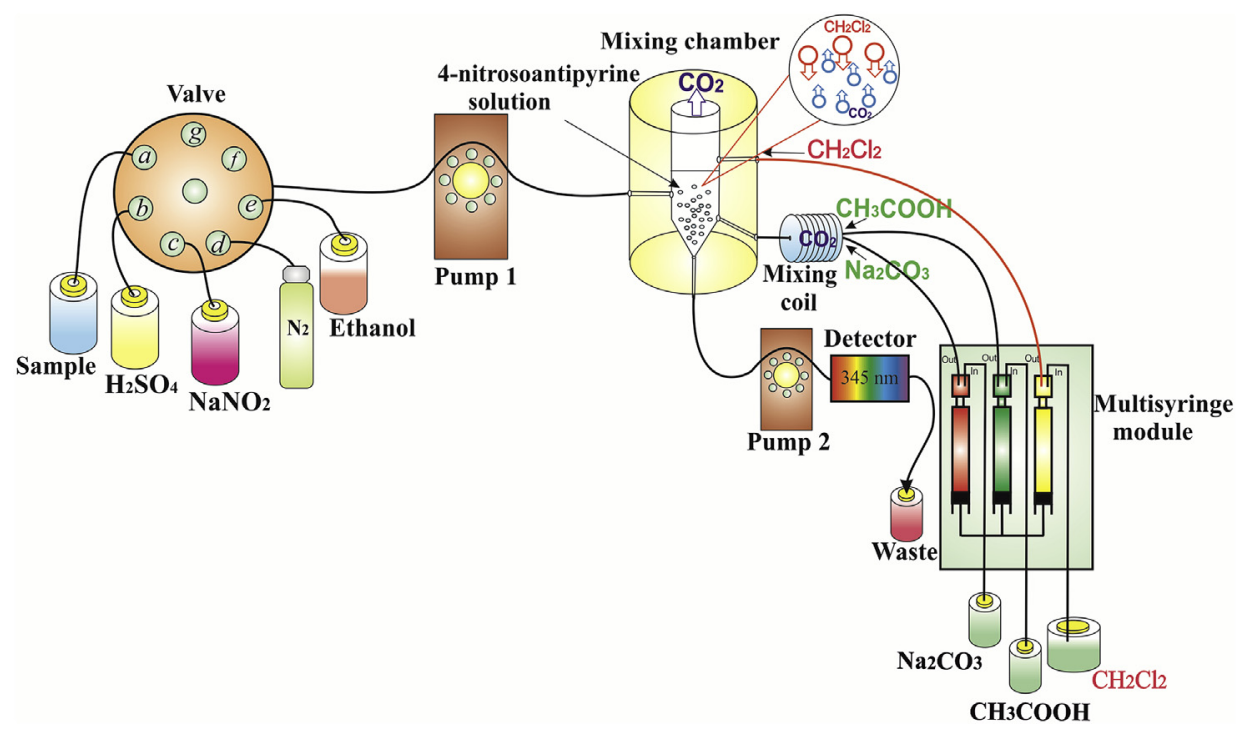

Fig. 1. The SWIA manifold for antipyrine determination with EA-DLLME.

(2) with modified PVC pumping tube (Watson-Marlow, Russia). The absorbance was measured under stop-flow conditions for $20 \mathrm{~s}$ at $345 \mathrm{~nm}$ wavelength. Afterwards, the extract and sample solution were delivered from MC to the waste. To avoid the memory effects between samples, the manifold was rinsed with $1 \mathrm{ml}$ of ethanol (port e).

\subsection{Instrumentation and procedure for reference HPLC-MS method for the determination of antipyrine}

$1 \mathrm{~mL}$ of chloroform was added to $1 \mathrm{~mL}$ of supernatant, and the mixture was mixed thoroughly. At the next stage, the mixture was centrifuged for $2 \mathrm{~min}$ at $3000 \mathrm{rpm}$. After that, the organic phase was collected, using syringe and put in polypropylene conical tube. The organic phase was evaporated from tube using water bath under the flow of argon and then, $0.5 \mathrm{~mL}$ of water was added.

HPLC-MS analysis was carried out on a Shimadzu LC-20 Prominence liquid chromatograph (Shimadzu Corporation, Kyoto, Japan). The chromatographic separation was achieved by Luna C18 column $(150 \mathrm{~mm} \times 4.6 \mathrm{~mm}, 5 \mu \mathrm{m}$ particle size). The procedure was taken from a standard protocol. A gradient program was employed for chromatographic separation with solvent A $\left(10 \mathrm{mmol} \mathrm{L}^{-1}\right.$ solution of triethylamine in water) and solvent B (acetonitrile). The injection volume was $0.5 \mu \mathrm{L}$. Linear gradient elution (SM Table 1 ) with a flow rate of $1 \mathrm{~mL} \mathrm{~min}^{-1}$ was used. The column temperature was conditioned at $35{ }^{\circ} \mathrm{C}$. A MaXis (Bruker Daltonik GmbH, Germany) mass spectrometer equipped with ESIQTOF source was used for mass spectrometric detection. The quantitative analyses of antipyrine and its metabolites in human saliva were performed using multiple reaction monitoring method (MRM) (SM Fig. 1). The dwell time was set to $200 \mathrm{~ms}$ for each MRM transition. The Masslynx 4.1 software (Waters Corp., Milford, MA, USA) was used for data acquisition and instrument control.

\section{Results and discussion}

Determination of antipyrine is based on its derivatization in the presence of nitrite-ions in an acidic medium, with the formation of colored 4-nitrosoantipyrine. Previously, it was found that, the rate of derivatization increases with increasing concentration of nitrite ions, and is almost completed within $3 \mathrm{~min}$, with $6 \mathrm{mmol} \mathrm{L}^{-1}$
$\mathrm{NaNO}_{3}, 0.5 \mathrm{~mol} \mathrm{~L}^{-1} \mathrm{H}_{2} \mathrm{SO}_{4}$, at temperature of $20 \pm 5{ }^{\circ} \mathrm{C}$, of optimal conditions [23]. Therefore, these conditions were selected as the default for further optimization.

\subsection{Investigation of appropriate conditions of EA-DLLME}

\subsubsection{Selection of the extraction solvent}

The requirements for extraction solvent in EA-DLLME are similar as in conventional DLLME: high efficiency for extraction of the target analyte and minimum signal of the blank test. Various extraction chlorinated solvents (chloroform, tetrachloromethane, dichloromethane and tetrachlorethylene) were investigated to have a higher density than water. Consequently, droplets of the organic phase, containing the analyte, were self-sedimented. It was found that, the most effective extractant is dichloromethane, which provides maximum extraction of 4-nitrosoantipyrine and minimum absorbance of the blank test (SM Fig. 2).

\subsubsection{Investigation of various injection modes}

Three different modes of injection of the solutions of effervescence agent, the proton donor, as well as, the extraction solvent into MC, containing derivatized antipyrine were investigated (Fig. 2). In all the cases, the solutions of the effervescence agent $\left(\mathrm{Na}_{2} \mathrm{CO}_{3}\right)$ and proton donor $\left(\mathrm{CH}_{3} \mathrm{COOH}\right)$ were mixed in the mixing coil. Afterwards, this mixed solution, containing carbon dioxide microbubbles, was delivered into the MC, containing derivatized antipyrine solution: in the first mode via bottom channel (1) of MC, while the extraction solvent was injected via bottom sideway channel (2) (Fig. 2A); in the second mode via bottom sideway channel (2) of MC, while the extraction solvent was injected via bottom channel (1) (Fig. 2B); and finally in the third mode via bottom sideway channel (2) of MC, while the extraction solvent was injected via top sideway channel (3) of MC (Fig. 2C). In all the cases, after the EA-DLLME procedure, the extract was passed through the bottom channel to the detector. The solution of the 4-nitrosoantipyrine was prepared separately from the working solution of antipyrine. The initial set of parameter values used was: 4-nitrosoantipyrine solution volume and concentration $-3 \mathrm{~mL}$ and $2 \mathrm{mg} \mathrm{L}^{-1}$, respectively. The flow rate of $2 \mathrm{~mL} \mathrm{~min}^{-1}$ and volume of $300 \mu \mathrm{L}$ were selected for each solution: $0.5 \mathrm{~mol} \mathrm{~L}^{-1} \mathrm{Na}_{2} \mathrm{CO}_{3}$, $1 \mathrm{~mol} \mathrm{~L}^{-1} \mathrm{CH}_{3} \mathrm{COOH}$ and dichloromethane.

The criteria for selecting injection mode were: highest analytical response, and better reproducibility, expressed by RSD. The 


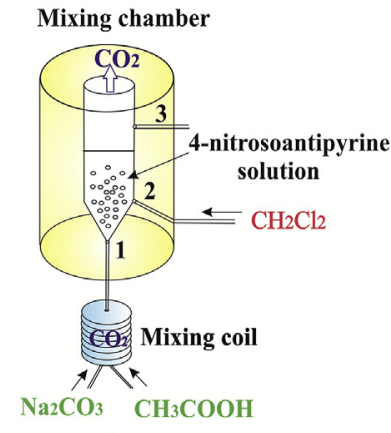

A

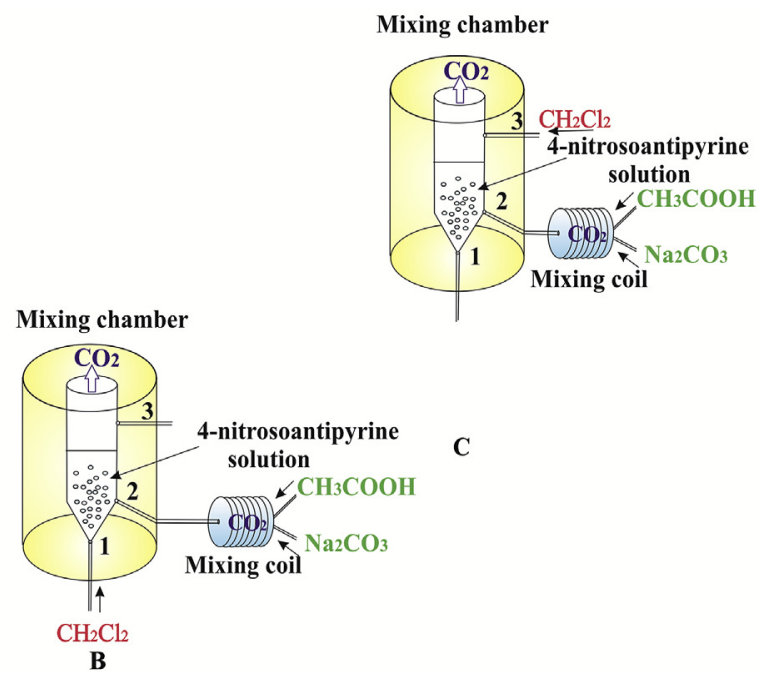

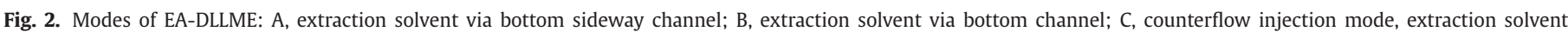
via top sideway channel.

results showed that the third counterflow injection mode is the most suitable (Fig. 3A). In this case, in situ formed $\mathrm{CO}_{2}$ microbubbles and extraction solvent are simultaneously directed from opposite ends and efficient dispersion of extraction solvent is observed leading to the extraction of the analyte. Therefore, this mode was selected for further experiments.

\subsubsection{Effect of flow rate and reagents concentration}

The flow rates for $\mathrm{CH}_{3} \mathrm{COOH}$ and $\mathrm{Na}_{2} \mathrm{CO}_{3}$ solutions were simultaneously varied from 0.5 to $5 \mathrm{~mL} \mathrm{~min}{ }^{-1}$. It was found (Fig. 3B) that flow rate of $1.5 \mathrm{~mL} \mathrm{~min}^{-1}$ provides the extraction efficiency and simultaneous minimum value of RSD. At higher flow rates, the dispersion of extraction solvent occurs faster but reproducibility is significantly reduced.

The effect of the concentration of $\mathrm{CH}_{3} \mathrm{COOH}$ and $\mathrm{Na}_{2} \mathrm{CO}_{3}$ from 0.2 to $2 \mathrm{~mol} \mathrm{~L}^{-1}$ and from 0.1 to $1 \mathrm{~mol} \mathrm{~L}^{-1}$, respectively was studied as well. Based on the results obtained (Fig. 3C, D), $1 \mathrm{~mol} \mathrm{~L}^{-1}$ $\mathrm{CH}_{3} \mathrm{COOH}$ and $0.5 \mathrm{~mol} \mathrm{~L}^{-1} \mathrm{Na}_{2} \mathrm{CO}_{3}$ were chosen for further experiments.

\subsection{Interference effect}

The effect of major saliva compounds and the main metabolites of antipyrine (noratipyrine and 4-hydroxyanipyrine) on the SWIA
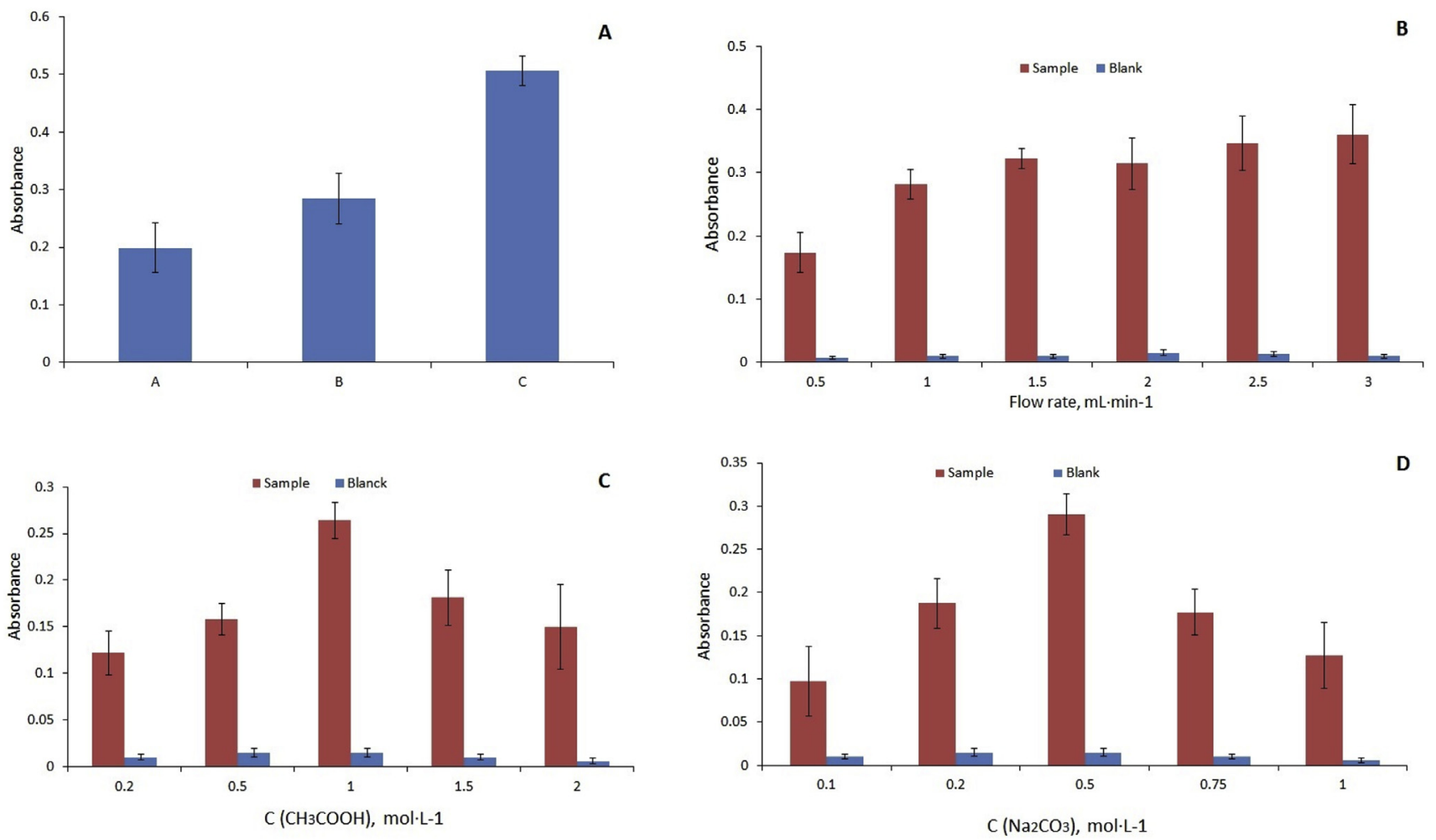

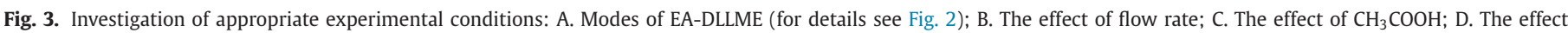
of $\mathrm{Na}_{2} \mathrm{CO}_{3}$. 
Table 1

Comparison of the developed method with existing methods for antipyrine determination in saliva.

\begin{tabular}{|c|c|c|c|c|c|c|c|}
\hline Detection technique & Sample pretreatment & Fully automated technique & Linear range, $\mu \mathrm{mol} \mathrm{L}^{-1}$ & LOD, $\mu \mathrm{mol} \mathrm{L}^{-1}$ & RSD, \% & Time of analysis, min & Ref. \\
\hline MECC & Deprotonization, separation & No & $30-350$ & 10 & 4.8 & 8 & [31] \\
\hline LC-UV & Deprotonization, separation & No & $3-100$ & 1 & 8.8 & - & [32] \\
\hline LC & LLE, evaporation and dissolution & No & $5-50$ & 1.5 & 4.3 & 10 & [33] \\
\hline HPLC & LLE, evaporation and dissolution & No & $5-250$ & 0.5 & 7 & 15 & [34] \\
\hline SWIA & Derivatization and DLLME & Yes & $3-200$ & 1 & 2.5 & 12 & [23] \\
\hline SWIA & Derivatization and EA-DLLME & Yes & $1.5-100$ & 0.5 & 2.5 & 10 & This work \\
\hline
\end{tabular}

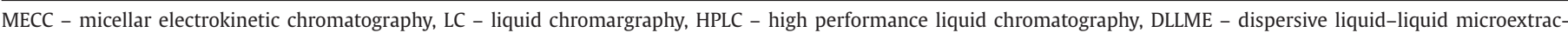
tion, SWIA - stepwise injection analysis, EA-DLLME - effervescence assisted dispersive liquid-liquid microextraction.

determination of antipyrine was also investigated. This was done by adding known concentrations of each compound in order to fix $\mathrm{Cl}^{-}, \mathrm{PO}_{4}{ }^{3-}, \mathrm{SCN}^{-}, \mathrm{HCO}_{3}{ }^{-}$, noratipyrine and 4-hydroxyanipyrine concentrations into $20 \mu \mathrm{mol} \mathrm{L}^{-1}$ solution of antipyrine. The tolerable concentration of each taken foreign compound is considered to be less than $5 \%$ of relative error in the signal. At least more than 100 -fold excess of $\mathrm{Cl}^{-}, \mathrm{PO}_{4}{ }^{3-}, \mathrm{SCN}^{-}$and $\mathrm{HCO}_{3}{ }^{-}$is tolerated for the determination of antipyrine. It was found, that noratipyrine and 4-hydroxyanipyrine interfered even at their 1-fold and 100fold excess, respectively. Thus, the content of noratipyrine and 4hydroxyanipyrine in saliva samples $3 \mathrm{~h}$ after antipyrine ingestion was studied using HPLC-MS method. It was established that noratipyrine and 4-hydroxyanipyrine are in combined state with proteins, and therefore, it was concluded that metabolites interference was be negligible.

\subsection{Analytical performance}

Under optimal conditions, the proposed method is characterized by a linear calibration range of $1.5-100 \mu \mathrm{mol} \mathrm{L}^{-1}$ of antipyrine in saliva $(A=(0.1893 \pm 0.0038) \cdot[C]$, where $A$ is absorbance, $C$ is concentration of antipyrine in $\left.\mu \mathrm{mol} \mathrm{L}^{-1}\right)$, with correlation coefficient $\left(\mathrm{r}^{2}\right)$ of 0.998 , and the limit of detection is $0.5 \mu \mathrm{mol} \mathrm{L}-1(3 \sigma)$. The method repeatability expressed as RSD $(\mathrm{n}=10)$ is $2.5 \%$ and $2 \%$ at $1.5 \mu \mathrm{mol} \mathrm{L}{ }^{-1}$ and $100 \mu \mathrm{mol} \mathrm{L}^{-1}$, respectively. The sampling rate is 10 samples $\mathrm{h}^{-1}$. Comparison of the analytical performance of the proposed method with existing methods for determination of antipyrine in saliva is presented in Table 1. The data show the proposed method is superior with respect to all key analytical figures of merit. The described method is fully automated and more sensitive [23], since the application of dispersive solvent that can affect the solubility of the analyte in the aqueous phase is avoided.

\subsection{Application}

The proposed procedure was applied for the analysis of saliva samples. Approval was obtained from the Ethical Committee of Saint Petersburg State University Hospital. The obtained results showed no significant differences in antipyrine concentration obtained by the suggested and the reference method (Table 2). The

Table 2

Comparison of results of determination of antipyrine in saliva ( $\mathrm{n}=5, \mathrm{P}=0.95$, $\mathrm{F}_{\mathrm{kr}}=6.9$ ).

\begin{tabular}{llll}
\hline Volunteer & \multicolumn{2}{l}{$\begin{array}{l}\text { Antipyrine concentration, } \\
10^{-6} \mathrm{~mol} \mathrm{~L}^{-1}\end{array}$} & F-test \\
\cline { 2 - 3 } & SWIA & HPLC-MS & \\
\hline No 1 & $4.1 \pm 0.2$ & $4.0 \pm 0.2$ & 3.6 \\
No 2 & $23 \pm 1$ & $24 \pm 1$ & 4.0 \\
No 3 & $50 \pm 2$ & $48 \pm 2$ & 3.3 \\
\hline
\end{tabular}

paired t-test shows the antipyrine contents found using the EADLLME-SWIA method were insignificantly different from those obtained by the HPLC-MS method at a $95 \%$ confidence level.

\section{Conclusions}

The most important features of the EA-DLLME over conventional DLLME are: acceleration of phase equilibrium and phase separation and in situ generation of $\mathrm{CO}_{2}$ as dispersive force instead of the addition of a dispersive solvent [12]. The EA-DLLME now is fully automated based on stepwise injection analysis manifold. Various arrangements of the suggested manifold were tested. The results show that, the counterflow injection mode in which in situ formed $\mathrm{CO}_{2}$ microbubbles and extraction solvent are simultaneously directed from opposite ends of the mixing chamber is the most suitable. Formation of microbubbles leads to thorough dispersion of the extraction solvent in the whole aqueous sample, and resulting in efficient extraction of the analyte into the organic phase. The application of dispersive solvent, as well as, timeconsuming centrifugation step for the disruption of cloudy state is avoided. The phase separation was achieved by gentle flow of nitrogen stream. The efficiency of the developed procedure was demonstrated by determination of antipyrine in saliva samples. The suggested approach can also be applied to procedures for the determination of other analytes in different samples.

\section{Acknowledgments}

The authors acknowledge funds from the Russian Foundation for Basic Research (Project no. 13-03-00031-a, 14-03-31092 mol_a and 15-33-20068), the Scientific Grant Agency of the Ministry of Education of the Slovak Republic (Grant no. VEGA 1/0010/15), the European Social Fund (ESF) (Project KVARK code: ITMS 26110230084). Scientific research was performed at the Center for Chemical Analysis and Materials Research of St. Petersburg State University.

\section{Appendix A. Supplementary data}

Supplementary data related to this article can be found at http://dx.doi.org/10.1016/j.aca.2015.11.017.

\section{References}

[1] Y. Chen, Z. Guo, X. Wang, C. Qiu, Sample preparation, J. Chromatogr. A 1184 (2008) 191-219.

[2] J. Pawliszyn, Sampling and Sample Preparation for Field and Laboratory: Fundamentals and New Directions in Sample Preparation, Elsevier, 2002.

[3] S. Armenta, S. Garrigues, M. de la Guardia, Green analytical chemistry, Trends Anal. Chem. 27 (2008) 497-511.

[4] A. Spietelun, Ł. Marcinkowski, M. De La Guardia, J. Namieśnik, Green aspects, developments and perspectives of liquid phase microextraction techniques, Talanta 119 (2014) 34-45.

[5] A.A. Cardosot, P.K. Dasgupta, Analytical chemistry in a liquid film/droplet, Anal. Chem. 67 (1995) 2562-2566. 
[6] M. Rezaee, Y. Assadi, M.-R. Milani Hosseini, E. Aghaee, F. Ahmadi, S. Berijani, Determination of organic compounds in water using dispersive liquid-liquid microextraction, J. Chromatogr. A 1116 (2006) 1-9.

[7] J. Regueiro, M. Llompart, C. Garcia-Jares, J.C. Garcia-Monteagudo, R. Cela, Ultrasound-assisted emulsification-microextraction of emergent contaminants and pesticides in environmental waters, J. Chromatogr. A 1190 (2008) 27-38.

[8] Q. Wu, Q. Chang, Ch Wu, H. Rao, X. Zeng, Ch Wang, Z. Wang, Ultrasound assisted surfactant-enhanced emulsification microextraction for the determination of carbamate pesticides in water samples by high performance liquid chromatography, J. Chromatogr. A 1217 (2010) 1773-1778.

[9] E. Yantzi, E. Psillakis, K. Tyrovola, N. Kalogerakis, Vortex-assisted liquidliquid microextraction of octylphenol, nonylphenol and bisphenol-A, Talanta 80 (2010) 2057-2062.

[10] Z.H. Yang, Y.L. Lu, Y. Liu, T. Wu, Z.Q. Zhou, D.H. Liu, Vortex-assisted surfactantenhanced-emulsification liquid-liquid microextraction, J. Chromatogr. A 1218 (2011) 7071-7077.

[11] V. Andruch, M. Burdel, L. Kocúrová, J. Šandrejová, I.S. Balogh, Application of ultrasonic irradiation and vortex agitation in solvent microextraction, Trends Anal. Chem. 49 (2013) 1-19.

[12] G. Lasarte-Aragonés, R. Lucena, S. Cárdenas, M. Valcárcel, Effervescenceassisted dispersive micro-solid phase extraction, J. Chromatogr. A 1218 (2011) 9128-9134.

[13] G. Lasarte-Aragonés, R. Lucena, S. Cárdenas, M. Valcárcel, Effervescenceassisted carbon nanotubes dispersion for the micro-solid-phase extraction of triazine herbicides from environmental waters, Anal. Bioanal. Chem. 405 (2013) 3269-3277.

[14] G. Lasarte-Aragonés, R. Lucena, S. Cárdenas, M. Valcárcel, Effervescence assisted dispersive liquid-liquid microextraction with extractant removal by magnetic nanoparticles, Anal. Chem. Acta 807 (2014) 61-66.

[15] W. Jiang, X. Chen, F. Liu, X. You, J. Xue, Effervescence-assisted dispersive liquidliquid microextraction using a solid effervescent agent as a novel dispersion technique for the analysis of fungicides in apple juice, J. Sep. Sci. 37 (2014) 3157-3163.

[16] X. Liu, Z. Shen, P. Wang, C. Liu, Z. Zhou, D. Liu, Effervescence assisted on-site liquid phase microextraction for the determination of five triazine herbicides in water, J. Chromatogr. A 1371 (2014) 58-64.

[17] S. Molaei, A. Saleh, V. Ghoulipour, Sh. Seidi, Dissolved carbon dioxide flotation: an effective way for phase separation in emulsification microextraction method, J. Chromatogr. A 1388 (2015) 280-285.

[18] L. Kocúrová, I.S. Balogh, V. Andruch, Solvent microextraction: A review of recent efforts at automation, Microchem. J. 110 (2013) 599-607.

[19] A.N. Anthemidis, M. Miró, Recent developments in flow injection/sequential injection liquid-liquid extraction for atomic spectrometric determination of metals and metalloids, Appl. Spectrosc. Rev. 44 (2009) 140-167.

[20] A.N. Anthemidis, K.-I.G. Ioannou, On-line sequential dispersive liquid-liquid microextraction system for flame atomic absorption spectrometric determination of copper and lead in water samples, Talanta 79 (2009) 86-91.
[21] F. Maya, B. Horstkotte, J.M. Estela, V. Cerda, Automated in-syringe dispersive liquid-liquid microextraction, Trends Anal. Chem. 59 (2014) 1-8.

[22] V. Andruch, C.C. Acebal, J. Škrlíková, H. Sklenářová, P. Solich, I.S. Balogh, F. Billes, L. Kocúrová, Automated on-line dispersive liquid-liquid microextraction based on a sequential injection system, Microchem. J. 100 (2012) 77-82.

[23] A. Bulatov, K. Medinskaia, D. Aseeva, S. Garmonov, L. Moskvin, Determination of antipyrine in saliva using the dispersive liquid-liquid microextraction based on a stepwise injection system, Talanta 133 (2015) 66-70.

[24] R. Suárez, B. Horstkotte, C.M. Duarte, V. Cerdà, Fully-automated fluorimetric determination of aluminum in seawater by in-syringe dispersive liquid-liquid microextraction using lumogallion, Anal. Chem. 84 (2012) 9462-9469.

[25] M. Falkova, A. Bulatov, M. Pushina, A. Ekimov, G. Alekseeva, L. Moskvin, Mul ticommutated stepwise injection determination of ascorbic acid in medicina plants and food samples by capillary zone electrophoresis ultraviolet detection, Talanta 133 (2015) 82-87.

[26] I. Timofeeva, I. Khubaibullin, M. Kamencev, A. Moskvin, A. Bulatov, Automated procedure for determination of ammonia in concrete with headspace singledrop micro-extraction by stepwise injection spectrophotometric analysis, Talanta 133 (2015) 34-37.

[27] C. Fulmes, A. Bulatov, O. Yasakov, E. Freze, A. Moskvin, Y. Dedkov, L. Moskvin, Multicommutated stepwise injection analysis as new approach for simultaneous determination of nickel (II), copper (II) and zinc (II) in wet aerosols, Microchem. J. 110 (2013) 649-665.

[28] A. Bulatov, A. Petrova, A. Vishnikin, L. Moskvin, Stepwise injection spectrophotometric determination of cysteine in biologically active supplements and fodders, Microchem. J. 110 (2013) 369-437.

29] C. Vakh, A. Bulatov, A. Shishov, A. Zabrodin, L. Moskvin, Determination of silicon, phosphorus, iron and aluminum in biodiesel by multicommutated stepwise injection analysis with classical least squares method, Fuel 135 (2014) 198-204.

[30] G.M. Roche, B.S. Portz, W.G. Rector, G.T. Everson, Simultaneous determination of caffeine and antipyrine in plasma and saliva using high-performance liquid chromatography, J. Liq. Chromatogr. 13 (1990) 3493-3505.

[31] D. Perrett, G.A. Ross, Rapid determination of drugs in biofluids by capillary electrophoresis measurement of antipyrine in saliva for pharmacokinetic studies, J. Chromatogr. A 700 (1995) 179-186.

[32] A. El-Yazigi, D. Raines, A. Sieck, P. Ernst, M. Dossing, Simplified determination of antipyrine clearance by liquid chromatography of a microsample of saliva or plasma, Pharm. Res. 8 (1991) 269-272.

[33] G.M. Roche, B.S. Portz, W.G. Rector, G.T. Everson, Simultaneous determination of caffeine and antipyrine in plasma and saliva using high-performance liquid chromatography, J. Liq. Chromatogr. 13 (1990) 3493-3505.

[34] H. Echizen, M. Nakura, I. Ishizaki, Rapid and simple high-performance liquid chromatographic determination of saliva antipyrine for routine antipyrine test, J. Chromatogr. B 526 (1990) 296-299. 